\title{
Smart packaging : Modern way for reducing post-harvest losses of horticultural produce
}

\author{
Udit Joshi*, T.S. Bisht ${ }^{1}$, Laxmi Rawat and Ajay Mamgain \\ Plant Pathology Division, College of Forestry (V.C.S.G. Uttarakhand University of Horticulture and Forestry), \\ Ranichauri (Uttarakhand) India (Email: Uditjoshi444@gmail.com)
}

\begin{abstract}
Most fresh horticultural commodities are highly perishable and thus require proper care and handling during and after harvesting. Hence, packaging (pre-packaging, primary, secondary and tertiary) becomes an essential operation in prolonging the shelf life of the processed or fresh horticultural produce. Packaging provides containment and protection to the product and convenience and communication about the inside product to the end consumer. Consumer requirements and demands and world wide shifting patterns such as expectation of life and companies putting money into the production and delivery of food are driving innovation in food and packaging. Smart packaging is a novel and fascinating technological area with a lot of positive feedback from today's consumers. The two primary forms of smart packaging are active and intelligent packaging. Active packaging systems include active compounds put into sachets or pads and then placed in the package, as well as placed directly in the package or on the packaging material. Intelligent packaging comprises signs that describe the product's safety and quality, history, and the environment surrounding the container. Packaging in the traditional sense functions as a passive barrier, delaying the detrimental impact of environmental factors on the food product. These new innovative packaging systems, on the other hand, allow the package to interact with the environment and food, as well as play a vital part in the preservation of horticultural commodities. Despite substantial study into the innovative packaging technologies, several of these innovations have yet to be successfully deployed in commercial horticultural produce packaging systems. Comprehensive awareness of their potential in horticulture product packaging applications will help with effective development and broad commercial introduction.
\end{abstract}

Key Words : Active packaging, Intelligent packaging, Horticultural produces, Shelf life

View Point Article : Joshi, Udit Bisht, T.S., Rawat, Laxmi and Mamgain, Ajay (2021). Smart packaging : Modern way for reducing postharvest losses of horticultural produce. Internat. J. agric. Sci., 17 (AAEBSSD) : 331-339, DOI:10.15740/HAS/IJAS/17-AAEBSSD/331339. Copyright@2021: Hind Agri-Horticultural Society.

Article History : Received : 06.07.2021; Accepted : 15.07.2021

\section{INTRODUCTION}

India is a horticulturally diverse country producing a vast range of vegetables, fruits, spices and medicinal plants. Horticulture contributes 25.431 million hectares of land (around $18 \%$ of agricultural land) and produces about 311.741 million tonnes. India ranks second in producing vegetables and fruitsglobally, with an annual production of 97.358 and 184.394 MT, respectively (Anonymous ${ }^{1}, 2017-18$ ). However, about 25 to $30 \%$ of

\footnotetext{
*Author for correspondence:

${ }^{1}$ Department of Horticulture, School of Agriculture and Allied Sciences, H.N.B. Garhwal University (A Central University), Srinagar, Garhwal (Uttarakhand) India (tejpalbisht23@gmail.com)
} 
Udit Joshi, T.S. Bisht, Laxmi Rawat and Ajay Mamgain

\begin{tabular}{|c|c|}
\hline Postharvest changes & Detrimental effects after harv esting of produces \\
\hline Respiration & $\begin{array}{l}\text { Losses in stored food reserve leading to reduced energy value, loss in quality(odour/flavour), enhanced senescence, and } \\
\text { increased environmental heat loads. }\end{array}$ \\
\hline Ethylene production & $\begin{array}{l}\text { Degradation of chlorophyll in leafy vegetables, degradation of pectin and other polysaccharides, reduction in vitamin content, } \\
\text { and lignification leading to a rough texture (Rathore et al.,2012). }\end{array}$ \\
\hline Water loss & Wilting and shriveling leading to less consumer acceptance, loss of softness and crispness, and juiciness. \\
\hline Physiological dis orders & $\begin{array}{l}\text { Tissue necrosis and cell disrup tion leading to textural losses, colour losses, water-soaked lesions, improper ripening, and off- } \\
\text { flavour development (Nath et al., 2018). }\end{array}$ \\
\hline Physical damage & External browning, increased water loss, sites prone to fungal infection, and $\mathrm{CO}_{2}$ and ethylene production (Utto et al., 2005). \\
\hline Pathogenic breakdown & Fungal growth accelerated, leading to lesion formation, metabolism accelerated, and stimulation of tissue softening. \\
\hline
\end{tabular}

the horticultural produce is lost per year in India because of a lack of appropriate infrastructure and a lack of usage of precise post-harvest technology (Nath et al., 2018). Fresh horticultural products have a short shelf life, varying from some hours to a few weeks when stored at room temperature (Deval et al., 2013).

\section{Packaging:}

The packaging is a vital part of the post-harvest handling of products and provides fresh-attractive products to the users. Containment is the most fundamental function of the package, and it also serves as protection and provides information regarding the products. Even fresh produce exhibited in the store unpackaged must be carried out from the store in certain kinds of containers (Patel and Singh, 2009). It serves as a protection from gases, water, micro-organisms, dust, and punctures adulteration. Hence Packagingis a system by which fresh or processed product reaches from the production houses to the consumer in a sound condition (Rooney, 1997). Without packaging, the commodity would have suffered significant physical, chemical, and microbiological losses. It would have been complicated tohandle, manage, transport, and market the products as loose and unpacked. The packaging of fresh and processed commodities was needed to contain, unitize and protect the produce (Sharma and Nautiyal, 2009).

\section{Basic functions of packaging: Containment:}

The package contains the product andprevents any leakage, pilferage, and other losses. It is a crucial and primary function of packaging as a packaging material is a container for the packed product. It keeps the product in limited volume and prevents material overflow from the package (Sharma and Nautiyal, 2009; Kaur and Puri, 2017).

\section{Unitization:}

The package unitizes the product in suitable sizes for storage, transportation, marketing, and distribution depending on the requirement (Sharma and Nautiyal, 2009).

\section{Protection:}

Protection is a very crucial function of the packaging system. A package protects the packed product from external environmental conditions like heat, gases, microbes, etc. it also prevents the leakage and breakage of the product (Sharma and Nautiyal, 2009; Robertson, 2005).

\section{Information:}

The packagealso displays essential information about the contents.A package should provide all the necessary information about the product inside, such as nutritional content, manufacturing and expiring dates, quantity, information about manufacturing and marketing agencies, etc. (Priyanka and Parag, 2013).

\section{Convenience:}

A package gives the consumer ease to know about the product more and how to use the product. It also helps the consumer judge the product's quality (Majid et al., 2016).

\section{Advertisement:}

Packages of different brands of products may be of different shapes, colours and depict different attributes of the product. This is why we readily identify Frooti 
Smart packaging : Modern way for reducing post-harvest losses of horticultural produce

tetrapack or Pepsibottle even from some distance and without reading anything (Sharma and Nautiyal, 2009).

Keeping in view the amount of post-harvest losses faced in the case of horticulture products, the focus of the experts is on technological innovations that incorporate digital data into the packaging. Advances in digital printing, ingredients, and operations that can make packaging that can carry digital machinereadable data have assisted this (Dobrucka and Cierpiszewski, 2014). These advancements are focused on novel materials (such as printed polymers and inks) as well as tagging applications that are described as"Intelligent," "Smart," or "Active" packaging (Priyanka and Parag, 2013).

\section{Passive packaging:}

Passive packaging is a type ofconventional packaging involving covering material and protective covers for handling characteristics. It only supplies fundamental properties to the material, i.e., Presentation, Preservation, and Protection. It does not contribute much more to enhancing storage life and indicating the freshness of the produce (Kaur and Puri, 2017; Mir et al.,2018).

\section{Active packaging:}

In this type of packaging system, the contents inside the packaging material react to various environmental factors for keeping the inside environment of the package suitable for the products. For instance, filling the package with an oxygen scavenger, ethylene absorber, etc., leads to increased shelf-life of the product due to oxygen and ethylene absorption (Han et al., 2007). It generally focuses on improving the shelf life of the product but does not communicate the condition of the package (Priyanka and Parag, 2013; Mir et al., 2018).

\section{Intelligent packaging:}

Intelligent packaging makes innovations in the design of packaging, which makes a packaging material more communicable. It generally communicates the freshness of the produce, making it easier for the enduser to select the product easily (Priyanka and Parag, 2013). It indicates the typical freshness and leakage condition of the package. It might tell the microbial state of the package, but such systems are not commercially available at present.

\section{Smart packaging:}

Smart packaging is packaging with advanced features. It entails applying technology to add features so that packaging becomes an indispensable component of the whole product.The smart packaging reacts to changes in the environment and depicts the alteration in the package. Electrical, chemical, electronic, or mechanical technologies, or their blends, are used in smart packaging (Yam et al., 2005; Day, 2008).

\section{Active and intelligent packaging:}

Traditional packaging covers the fundamental work of the packaging, such as containment, protection, information, and convenience but that too to a bit of extent (Rooney, 1997). Over time, the world is becoming complex, creating high demands for innovative packaging because of it sad vancement and creativeness over the present ones. Active and intelligent packaging results from evolving thinking in the packaging industries (Majid et al., 2016).

\section{active packaging:}

Active packaging can be described as packaging in which secondary elements have been purposefully placed on or around the packaging or package area to improve the package system's performance (Robertson, 2005). It is an extension of the protection function of a package, and it protects the package against oxygen, moisture, and environmental harshness to enhance the storage life of the produce (Barbosa et al., 2016). It performs both traditional and modern functions of packaging, such as providing barriers to gases, moisture, and vapour, hindering contamination of food from outside, and creating feasible food identification and handling (Ozdemir and Floros, 2004). Active technologies are generally seen in two systems. Firstly, Sachets or padskept inside the package: They are suitable for solid foods, but they are challenging to use in liquid foods. They areattached to the package where they function correctly. Absorbent pads may absorb liquid orgases and infuse them with silver, copper, or copper oxide nanoparticles. Secondly, Active ingredients are incorporated in the package in films and coatings (Otoni et al., 2016).

\section{Applications of active packaging: \\ Oxygen scavengers \\ Carbon dioxide emitters and absorbers \\ Moisture (humidity and condensation) regulators}


Udit Joshi, T.S. Bisht, Laxmi Rawat and Ajay Mamgain

\begin{tabular}{|c|c|c|c|}
\hline System & Mechanism & Manufacturer & Trade name \\
\hline $\mathrm{O}_{2}+\mathrm{CO}_{2}$ scavenging & $\begin{array}{c}\text { Iron-based } \mathrm{O}_{2} \text { scavenging powder }+\mathrm{Ca} \\
(\mathrm{OH})_{2}+\text { Ascorbic acid }\end{array}$ & $\begin{array}{c}\text { Mitsubishi Gas Chemical Ltd., Japan } \\
\text { Toppan Printing Co. Ltd., Japan }\end{array}$ & $\begin{array}{c}\text { Ageless }{ }^{\circledR} \text { E, Fresh Lock }{ }^{\circledR} \text { and } \\
\text { Freshilizer }{ }^{\circledR}\end{array}$ \\
\hline $\begin{array}{l}\mathrm{O}_{2} \text { scavenging and } \mathrm{CO}_{2} \\
\text { releasing }\end{array}$ & $\begin{array}{c}\text { Ascorbic acid }+ \text { Iron-based } \mathrm{O}_{2} \\
\text { scavenging powder }\end{array}$ & $\begin{array}{c}\text { Mitsubishi Gas Chemical Ltd., Japan } \\
\text { Toppan Printing Co. Ltd., Japan } \\
\text { Toagosei Chemical Co. (Japan) }\end{array}$ & Ageless ${ }^{\circledR}$, Freshilizer ${ }^{\circledR}$, and Vitalon ${ }^{\circledR}$ \\
\hline
\end{tabular}

Source: Utto et al., 2005

Ethylene scavengers

Antimicrobial packaging

Flavour/odour absorbers.

\section{Oxygen scavengers:}

The presence of oxygeninside a packaged product often hinders the storability of the product. It causes oxidation of products, leading to change in colour, odour, and flavour; it also destroys nutrients present in the food and induces the growth of aerobic insects, moulds, and bacteria (Sanjeev and Ramesh, 2006). $\mathrm{O}_{2}$ scavenging methods now in use rely on the oxidation of one or more substances such as ascorbic acid, iron powder, photosensitive dye, and others. Rice extract, Immobilized yeast on a solid substrate, Enzymes (such as glucose oxidase and ethanol oxidase), Unsaturated fatty acids (such as oleic, linoleic, and linolenic acids) (Jain et al., 2017). Oxygen scavengers are available as Sachets, Plastic films, Labels, Crown caps, etc. The most commonly used $\mathrm{O}_{2}$ scavenger is powdered iron, as it gives a large surface area for reaction (Kaur and Puri, 2017). The overall reaction is as follows:

$4 \mathrm{Fe}(\mathrm{OH})_{2}+\mathrm{O}_{2}+2 \mathrm{H}_{2} \mathrm{O} \longrightarrow 4 \mathrm{Fe}(\mathrm{OH})_{3}$

A low level of available oxygen inside the package reduces respiration and ethylene production and enhances the shelf life of the produce (Gorny et al., 2002 and Oms-Oliu et al., 2008). Some aerobic microbes, i.e., Pseudomonas spp., Aspergillus and Penicillium spp. and facultative microorganisms such as Entero bacteriaceae can grow in an oxygen concentration of 1$2 \%$. Hence it is preferable to use an oxygen scavenger combined with MAP and vacuum packaging. Absorbers can decrease the oxygen concentration in the package head space by $0.01 \%$. Different size variations of oxygen scavengers utilize 20-2000mL of oxygen (Kaur and Puri, 2017). Breathable packaging or Gas permeable packaging allows gas exchange between the internal and external atmospheres of the package. A three-layer breathable film with more excellent permeability to gases was also developed to extend the storage life of fresh vegetable salads (Jain et al., 2017).

\section{Carbon dioxide emitters and absorbers:}

There are significantly fewer sachets that absorb carbon dioxide. Carbon dioxide absorbers can be of two types, i.e., Containing physical absorbent (zeolite) and chemical absorbent (Calcium hydroxide). Carbon dioxide affects the quality of food products both in high and low concentrations. To prevent pressure, swelling, and even bursting of the package of respiring foods, $\mathrm{CO}_{2}$ adsorption is utilized. $\mathrm{CO}_{2}$ emission is activated by moisture buildup leading to increased metabolism (Ozdemir and Floros, 2004).Physical absorbent zeolite adsorbs $\mathrm{CO}_{2}$ effectively.

Furthermore, the use of dual-action systems consisting of either an $\mathrm{O}_{2}$ scavenger plus a $\mathrm{CO}_{2}$ scavenger or an $\mathrm{O}_{2}$ scavenger plus a $\mathrm{CO}_{2}$ emitter has been proposed for enhancing the storability of highly perishable foods. For $\mathrm{CO}_{2}$ scavenging, the use of soda lime, magnesium oxide, and activated charcoal has proved to be beneficial. Further studies of the technical and commercial feasibility of $\mathrm{CO}_{2}$ scavengers are required, as each must be optimized for a given product (Utto et al., 2005).

\section{Moisture (Humidity and Condensation) Regulators:}

Condensation or "sweating" is one of the significant concerns inpackaged foods, arising due to respiration and transpiration processes, which leads to spoilage, particularly in fresh fruit and vegetables. Excessive moisture can be controlled by applying drip absorbent sheets, which enclose a layer of a super absorbent polymer such as cellulose fibres or polyacrylate salts (Jain et al., 2017). Along with this, propylene glycol (Humectant) could be placed between two plastic films. Other moisture scavengers, including silica gel, natural clays (montmorillonite), calcium oxide, calcium chloride, and modified starch, can adjust package humidity (Day, 2008). Anti-fogging films are a helpful aid for consumers, which helps to see the packaged product through the packaging films, which encloses hydrophilic liners, 
humidity absorbers, or micro-perforations. Such coatings are commonly used to decrease internal vapour pressure and avoid water condensation in respiring items such as fresh vegetables and fruits (Ozdemir and Floros, 2004).

\section{Ethylene regulators:}

Ethylene which is also known as ripening hormone, causes softening in fresh and processed horticultural produce. It also aids the degradation of chlorophyll in green-leaved vegetables (Toivonen and Brummell, 2008). Hence controlling the ethylene concentration package extends the shelf life of produce. Ethylene controllers or regulators can be classified into two main categories: ethylene-removal and ethylene-antagonism.

Most of the ethylene absorbers are potassium permanganate-based (Kaur and Puri, 2017). The reaction of the functioning ofethylene absorber is as follow:

$$
3 \mathrm{C}_{2} \mathrm{H}_{4}+12 \mathrm{KMnO}_{4} \longrightarrow 12 \mathrm{MnO}_{2}+12 \mathrm{KOH}+6 \mathrm{CO}_{2}
$$

\section{Ethylene removal systems or ethylene scavengers:}

Ethylene scavengers areamong the most successful commercial active packaging systems applied to fresh fruit shipment. Oxidation or adsorption reactions remove ethylene from the packaging area (Freitas et al., 2017). Commonly used absorbents are silica, zeolite, activated carbon, and Japanese clay (Vermeiren et al., 2003). In oxidation systems, oxidizing agents such as $\mathrm{KMnO}_{4}, \mathrm{PdCl}$, or di-carboxyoctyl ester of tetrazine are immobilised onto adsorbents, and these oxidise ethylene to ethylene glycol, $\mathrm{CO}_{2}$, and water (Utto et al., 2005).

\section{Ethylene antagonist systems:}

Gases such as 1-methyl cyclopropane (1-MCP), and nitric oxide (NO), and nitrous oxide $\left(\mathrm{N}_{2} \mathrm{O}\right)$ is commercially usedas they inhibit ethylene-induced processes in horticultural products (Blankenship and Dole, 2003). These gasesbind to ethylene receptors and minimize the binding of ethylene during postharvest operations leading to delayed ethylene-induced metabolic processes and decreasevarious physiological disorders associated with ethylene. Only 1-MCP is used commercially among the ethylene antagonists and is marketed as Smart Fresh TM by Agro-Fresh Inc. for use on fruits, vegetables, and flowers such as apple, kiwifruit, avocado, tomato, and roses (Utto et al., 2005). Paul and Pandey (2013) carried out a demonstration of treatment of 1-MCP (Smart Fresh formulation containing
$0.14 \%$ of $1-\mathrm{MCP}$ as a.i.) @ 0.3 ppm of 1-MCP. This treatment delayed the ripening of tomato both at the green stage and turning stage by about 8-14 days and 4-8 days, respectively, depending upon cultivars used and storage temperatures. Lata et al. (2017) also explained the effectiveness of 1-MCP in the quality maintenance of fresh vegetables and fruits.

\section{Antimicrobial packaging:}

Antimicrobial materials prolong the lag phase of the growth curve and restrict microorganism growth. Microbial contamination and deterioration are caused mainly by unsanitary harvesting, transportation, packing, and processing. Freshly harvested fruits and vegetables carry several microorganisms such as Escherichia coli, lactic acid bacteria, Pseudomonas, and Erwinia. Yet, Yeasts, moulds, and Pseudomonas are the spoilage causing agents offruits and vegetables. Antimicrobial packaging releases agents that keep the surface concentration of the agent above the MIC (minimum inhibitory concentration) of the target microorganisms (Jain et al., 2017).

After being triggered by moisture,allyl isothiocyanate in cyclodextrin matrix in liners of plastic films is released into the package's headspace (Utto et al., 2005). Several agents used against microbial spoilage are Ag-zeolites (Silver-based), organic acids, nisin and pediocin (bacteriocins), hexamethylene tetraamine, lysozyme, fungicides (enzymes), and triclosan (organic compounds).

\section{Flavour/Odour absorbers:}

Flavour and odour absorbers remove undesirable gaseous molecules like volatile package ingredients, microbial metabolites, chemicals, respiration products, or off flavour/ odour developed in the package (Barbosa $e t$ al., 2014). Zeolite (synthetic aluminium silicate) is a porous structure that absorbs odorous aldehydes when included in packaging material.Coating plastic bottles with cellulose acetate butyrate absorbs limonin and immobilizesnaringinase in cellulose triacetate film (to hydrolyse naringin) helps in bitter compounds (limonin and naringin) removal from citrus juices (Priyanka and Parag, 2013).

\section{Modified atmosphere packaging (MAP):}

MA condition is generally characterized by the increased level of $\mathrm{CO}_{2}$ and decreased levels of $\mathrm{O}_{2}$ created by the respiration of fresh fruits and vegetables 
or by the active generation of MA. When a commodity is packed in such a way that modified atmosphere, i.e., reduction in $\mathrm{O}_{2}$ and increase in $\mathrm{CO}_{2}$ levels, is generated inside the package, it is called modified atmosphere packaging (Kaur and Puri, 2017). In a modified atmosphere package, the product is exposed to the standard atmospheric gases (oxygen, nitrogen, carbon dioxide, and water vapour). Still, the concentrations are different from those in the open air. The packaging consists of a polymeric film pouch or plastic container with a specified gas permeability. Both fresh and processed products can be packed in MAP (Priyanka and Parag, 2013). Examples of MAP in new commodities: Individual shrink wrapping of malta, capsicum, cucumber, brinjal, cabbage, etc. Flexible plastic packaging materials comprise nearly $90 \%$ of the materials used in MAP due to their wide range of permeability to gases and water vapour, alongwith necessary package integrity needed for MAP while, paper, paperboard, aluminium foil, metal, and glass containers account for only $10 \%$ in MAP (Jain et al., 2017).

\section{Intelligent packaging:}

Intelligent packaging is described as packaging that includes an internal or external signal that displays feedback about the package's history and/or product quality (Robertson, 2005). Intelligent packaging is an advancement above conventional packaging. It can sense, detect, record, and visualise alterations (both external and internal) in the product's environment, allowing it to transmit information to the end-user. It is one of the best tools for monitoring adulterations in food during supply chains (Dobrucka and Cierpiszewski, 2014). Various indicators such as the growth of microbes, temperature, the product's authenticity, and the integrity of the package are used in intelligent packaging (Pacholi et al., 2017). Currently, researchers are working on novel labels and seals that remain translucent until a box is opened or interfered with. Once the item is opened or tampered with, the label changes colour permanently and may even spell out "opened" or "stop." The following is an example of intelligent packaging: (Kaur and Puri, 2017)

Product quality indicators (Time-temperature indicator, Gas indicator, and Freshness indicator) Protection of products from tampering and theft Increasing convenience (Preparation and cooking of food)

\section{Product quality indicators: \\ Time- temperature indicator (TTI):}

TTI is a handy tool because it tells consumers when the packed product is temperature abused as the quality of the packed item deteriorates much quicker when it is exposed to a higher recommended temperature. TTI could be applied on individual packages or shipping containers as a tiny self-adhesive label that induces an irreversible colour change when exposed to temperature extremes.TTI is most widely used with frozen items, where maintaining a cool temperature during transit, storage, and distribution is critical for food quality and safety (Kaur and Puri, 2017).

Based on their response mechanism, TTIs can be categorised as partial history or full history indicators. Before surpassing a temperature threshold, partial history indicators do not respond, indicating that a product has been exposed to a temperature that might cause a change in product quality. The whole tale TTIs provide a constant temperature-dependent reaction throughout a product's life cycle and are the primary focus of research and commercialization (Kerry et al., 2006; Dobruckaand Cierpiszewski, 2014). Various TTI's currently marketed are Fresh-Check, Timestrip, Monitor Mark, and Check Point by companies $3 \mathrm{M}^{\mathrm{TM}}$, Timestrip Plc, Life Lines, and Vitsab.

\section{Gas indicators:}

Fresh horticulture products are challenging commodities to package since they may breathe and change their environment within a box. Gas indicators are valuable tools for monitoring the gaseous composition within a package because enzymatic chemical reactions affect the colour of the indicator (Yam et al., 2005). The presence or absence of carbon dioxide or oxygen in the package is indicated via gas indicators. Oxygen can induce oxidative rancidity, undesirable colour changes, and the growth of aerobic microorganisms on freshpacked products (Priyanka and Parag, 2013). Oxygen indicators indicate improper sealing of a package by changing the colour of the indicator due to oxidative reactions. Gas indicators are also being developed to detect water vapours, ethanol, and hydrogen sulphide (Anonymous $\left.{ }^{2}, 2013\right)$. One of the oxygen indicators commonly used is methylene blue (MB, methyl thionine chloride) which is a dye that changes its colour reversibly 
upon oxidation and reduction (Dobrucka and Cierpiszewski, 2014).

\section{Freshness indicator:}

Freshness indicators detect changes occurring inside a package ( $\mathrm{pH}$, gas composition, etc.). These changes get transformed into a colour response which can be correlated with the freshness of food. Freshness indicators based on target metabolites linked with microbiologically caused degradation can be produced using the chemical detection of food spoilage (Kuswandi et al., 2013). Various freshness indicators are based on the colour change of the indicator in response to microbial metabolites generated during deterioration. One of which is currently available in the market by Ripe Sense (Priyanka and Parag, 2013).

\section{Protection of products from theft and tempering:}

Theft is not a big concern in the case of food products while it is so for commodities like electronics and clothes; hence holograms, special inks, dyes, laser labels, and electronic tags are used for them, but their use in food packaging is limitedbecause of increases in the cost of the product by their usage. However, tampering is a primary concern in the case of the food industry. Tampering indicators change colour or show words like open or stop if the package is damaged or the seal is broken (Kaur and Puri, 2017).

\section{Increasing convenience in preparation and cooking of food thearmochromic inks:}

Thermochromic inks let consumers determine if a product is too hot to touch or too cold to drink (Anonymous ${ }^{2}$, 2013). Thermochromic inks are commonly used for beverages and have become a popular technology (Robertson, 2005).UV rays and temperatures above $121^{\circ} \mathrm{C}$ have a negative impact on inks; therefore, customers should not depend solely on the message of the inks when determining whether to consume food.

\section{Microwave doneness indicators (MDI):}

MDIs are devices that detect the readiness of meals maintained in microwave ovens for heating and alert users when they are ready to eat. However, the ability of the microwave to evenly heat the food is in question as foods heat non-uniformly, and hot spots occur throughout the food. While colder parts would not have achieved appropriate cooking temperatures, these hotspots provide a doneness signal (Anonymous ${ }^{2}, 2013$ ). The best MDI would be on the lid or dome of the microwave container so that the user could see the visual signal for doneness readily (Robertson, 2005). As of now, MDI's are not available commercially, but their arrival in the market is much anticipated.

\section{Smart packaging of the future:}

Todate, no specific methods are there to assess the effect of active or intelligent packaging with foods on their direct contact (Robertson, 2005). The problem arises when harmful substances from the sensor get migrated into the foods, creatingill health effects. Along with this, the cost of smart packaging is a bottleneck in their commercial use. The following are some new and innovative smart packaging idea that is in the works.

\section{Biosensors for pathogen or toxin indentification:}

Foodborne pathogens cause significant damage to the shelf life of produces, and many consumers are aware of this problem nowadays. A biosensor is a device that detects pathogens that can cause damage to the food stuffs and transmits this information into some sort of signal. In this case, antibodies are attached to the packaging surface to detect pathogens or toxins; as a result, when antibodies come into contact with pathogens, a visual cue is displayed to alert the consumer. However, this system requires extensive research to become commercially available.

\section{Radio frequency indentification (RFID):}

RFID tags are sophisticated data information carriers that track and identify products. Radio frequency identification (RFID) tags are expected to be used in food containers in the future (Yam et al.,2005). Currently, they are used for tracking expensive items and livestock. In this system, a reader sends out a radio signal that gathers data from an RFID tag, which is subsequently sent to a computer for processing. A microchip is linked to a small antenna in RFID tags (Sharma and Thakur, 2019). This enables a reading range of 100 feet or more in more costly tags and 15 feet in less expensive tags (Anonymous ${ }^{2}$, 2013).

They could be integrated with a TTI indicator or a biosensor to carry microbiological information and timetemperature information (Yam et al., 2000). In the food industry, RFID technology is still in its infancy. Most food science issues revolve around simple applications like 
tracking and identification, which must be solved before more complicated uses emerge.

\section{Advantages and limitations of smart packaging:}

Smart packaging retains integrity and actively prevents food spoilage hence extending shelf-life. They also improve the product's features (look, taste, flavour, aroma, etc.). They can control and even react to activities inside the package, and they generally respond actively to changes in the product or package environment. They also provide product information, product history, and other circumstances to the user. However, smart packaging has some drawbacks: its expensiveness than traditional packaging, and there are doubts about its performance. Certain substances released from packaging material can affect the product's composition, and before implementation, they require more knowledge and consumer awareness.

\section{Prospects:}

As new technologies are introduced to the market, smart packaging solutions will become more wide spread. Nanotechnologies will be used in the next phase of packaging technology, allowing new chemicals such as novel antimicrobials and gas scavengers to be incorporated in packaging films. The growth of low-cost electrical gadgets will also contribute to smart packaging's inventive path. Shortly, smart packaging may entirely replace traditional packaging.

\section{Conclusion:}

Along with changes in market competition and consumer behaviour, consumer preferences lead to more innovations and developments in the existing technologies; it is the same in the case of packaging technologies, which offers exciting chances for safety, integrity, quality, and convenience. Current $\mathrm{R}$ and D'sin the field of smart packaging materials are very complex and dynamic and lead to the search for eco-friendly packaging solutions. These will become more effective as the application of these solutions contributes more towards improving the quality of consumer life. The innovation systems require to improve the product quality along with enhancing the safety and security of products to decrease the number of retailer and consumer complaints and increase their acceptability.

\section{REFERENCES}

Anonymous $^{1}$ (2018). Indian Horticulture Database, National
Horticulture Board, Gurgaon.www.nhb.gov.in.

Anonymous $^{2}$ (2018). Active and intelligent packaging: Innovations for the Future.www.pacmanproject.eu.

Barbosa-Pereira, L., Aurrekoetxea, G.P., Angulo, I., PaseiroLosada, P. and Cruz, J.M. (2014). Development of new active packaging films coated with natural phenolic compounds to improve the oxidative stability of beef. Meat Sci.,97(2): 249254.

Blankenship, S.M. and Dole, J.M. (2003). 1Methylcyclopropene: a review. Post. Bio.Tech., 28: 1-25.

Day, B.P.F. (2008). Active packaging of food. In: Smart packaging technologies for fast moving consumer goods. Hoboken, N.J. (ed.) John Wiley, pp. 1-18.

Deval, D., Mishra, N.K. and Lal, R. L. (2013). Effect of postharvest treatments of organic acid and polysaccharide on the shelf life of litchi (Litchi chinensis Sonn.) cv. Rose Scented. Prog. Hort., 45(2): 265-267.

Dobrucka, R. and Cierpiszewski, R. (2014). Active and intelligent packaging food-research and development. Pol. J. Food Nutr. Sci.,64 (1): 7-15.

Freitas, W.E., Almeida, M.L., Morais, P.L., Moura, A.K. and Junior, R.S. (2017). Potassium permanganate effects on the quality and postharvest conservation of sapodilla (Manilkara zapotaL.) fruits under modified atmosphere. Acta Agronom., 66 (3): 331-337.

Gorny, J.R., Hess-Pierce, B., Cifuentes, R.A. and Kader, A.A. (2002). Quality changes in fresh-cut pear slices as affected by controlled atmospheres and chemical preservatives. Post. Bio. Technol., 24: 271-278.

Han, J.H. and Floros, J.D. (2007). Active packaging. In: Advances in Thermal and Non-Thermal Food Preservation. Tewari, G. and Juneja, V. (eds.) Blackwell Professional, pp. 167183.

Jain, V., Singh, A., Tiwari, A., Maurya, A.K., Pal, S., Kanth, N. and Hada, T.S. (2017). Active packaging of horticultural produce. Nutra. Food process. Tech. Innov. Sci .Res., 42(1): 252-257.

Kaur, S. and Puri, D. (2017). Active and intelligent packaging: A boon to food packaging. Int. J. Food Sci. Nutri.,2(4): 15-18.

Kerry, J.P., O'Grady, M.N. and Hogan, S.A. (2006). Past, current and po-tential utilization of active and intelligent packaging systems for meat and muscle-based products: AReview. Meat Sci., 74: 113-130.

Kuswandi, B., Maryska, C., Jayus, Abdullah, A. and Heng, L. H. (2013). Real-time on package freshness indicator for the guavas packaging. J. Food Meas. Char., 7(1): 29-39.

Lata, D., Kuchi, V.S. and Nayik, G. A. (2017). 1-methyl 
Smart packaging : Modern way for reducing post-harvest losses of horticultural produce

cyclopropane (1-MCP) for quality preservation of fresh fruit and vegetables. J. Post. Tech.,5(3): 9-15.

Majid, I.,Nayik, G.A., Dar, S.M. and Nanda, V. (2016). Novel food packaging technologies: Innovations and future prospective. J. Saudi Soc. Agri. Sci., 17: 454-462.

Mir, A.A., Sood, M. and Bandral, J.D. (2018). Effect of active packaging on quality and shelf life of peach fruits. Pharm. Inn. J., 7(40): 1076-1082.

Nath, A., Meena, L.R., Kumar, V. and Panwar, A.S. (2018). Postharvest management of horticultural crops for doubling farmer's income.J. Pharma. Phytochem.,1(2): 2682-2690.

Oms-Oliu, G., Soliva-Fortuny, R.and Mart'ýn-Belloso, 0. (2008). Edible coatings with anti-browning agents to maintain sensory quality and antioxidation properties of fresh-cut pears. Post. Biol. Technol., 50:87-94.

Otoni, C.G., Espitia, P.J.P., Avena-Bustillos, R.J. and McHugh, T.H. (2016). Trends in antimicrobial food packaging systems: Emitting sachets and absorbent pads. Food Res. Int.,83:6073.

Ozdemir, M. and Floros, J.D. (2004). Active food packaging technologies. Crit. Rev. Food Sci. Nutri., 44:185-193.

Pacholi, S., Likhitkar, S. and D'Souza, A. (2017). Active Packaging in keeping the food fresh. Int. J. Eng. Res. Adv. Tech.,3(9): 19-27.

Patel, T. and Singh, A. (2009). Effect of different modified atmosphere packaging (MAP) film and cold storage temperatures $\left(5,10\right.$ and $\left.15^{\circ} \mathrm{C}\right)$ on keeping quality of Gerbera (Gerbera jamesonii) flowers. Acta Hort., 84(7): 353-358.

Paul, V.andPandey, R.(2013). Delaying tomato fruit ripening by using 1-methyl cyclopropane (1-MCP) for better postharvest management: current status and prospects in India. Indian J. Plant Physio., 18: 195-207.

Priyanka, N.C. and Parag, N.D. (2013). Intelligent and active packaging. Int. J. Eng.Manag. Sci., 4(4): 417-418.
Rathore, N.S., Mathur, G.K. and Chasta, S.S. (2012). Postharvest management and processing of fruits and vegetables. Indian Council of Agriculture Research, New Delhi. pp. 25-30.

Robertson, G.L. (2005). Packaging of Horticultural Products. In: Food packaging: principles and practice. $2^{\text {nd }}$ ed. Robertson, G.L.(ed.) CRC Press, Boca Raton, pp. 42-56.

Rooney, M.L. (1997). Active packaging. In: The Wiley encyclopaedia of packaging technology. Brody, A.L. and Marsh, K.S. (ed.) New York, John Wiley \& Sons, Inc., pp.2-7.

Sanjeev, K. and Ramesh, M.N. (2006). Low oxygen and inert gas processing of foods. Crit. Rev. Food Sci. Nutri., 46: 423451.

Sharma, R. and Thakur, A. (2019).Innovations in packaging for enhancing shelf life of horticultural produce. Paper presented at National seminar on doubling income through sustainable and holistic agriculture Solan, Himachal Pradesh, India, pp. 35-43.

Sharma, S.K. and Nautiyal, M.C. (2009). Postharvest technology of horticultural crops - practical manual series2. New India Pub. Agency, New Delhi, India, pp. 20-25.

Toivonen, P.M.A. and Brummell, D.A. (2008). Biochemical base of appearance and texture changes in fresh-cut fruit and vegetables. Post. Biol. Technol., 48:1-14.

Utto, W., Mawson, A.J., Bronlund, J.E. and Wong, K.K.Y. (2005). Active Packaging Technologies for Horticultural Produce. Food New Zealand.,5(2): 26-29.

Vermeiren, L.F, Heirlings, F., Devlieghere and Debevere, J. (2003). Oxygen, ethylene and other scavengers. In: Novel food packaging techniques. Ahvenainen, R. (ed.) Cambridge, Woodhead Publishing Limited, pp. 22-49.

Yam, K.L. (2000). Intelligent packaging for the future smart kitchen. Packag. Tech. Sci.,13(2): 83-85.

Yam, K.L., Takhistov, P.T. and Miltz, J. (2005). Intelligent packaging: concepts and applications. J. Food Sci.,4(7):2225 .

$17^{\text {th }}$ Year

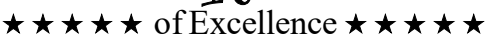

